\title{
Characterization of the Electrochemical Properties of Nitrogen- Doped Graphene
}

\author{
Jinyan Song ${ }^{1, *}$, Suling Wang $^{2}$, Xiaolei Wang ${ }^{3}$, Kai Wang ${ }^{4, *}$ \\ ${ }^{1}$ School of Information Engineering, Dalian Ocean University, Dalian; 116023, China \\ ${ }^{2}$ Department of Business Administration, Shandong Yingcai University, Ji'nan; 250104, China \\ ${ }^{3}$ Qingdao Hisense Electronic Equipment Co., Ltd., Qingdao; 266071, China \\ ${ }^{4}$ School of Electrical Engineering, Qingdao University, Qingdao; 266071, China \\ *E-mail: wkwj888@163.com and thesjyyan@163.com
}

doi: $10.20964 / 2021.01 .35$

Received: 6 May 2020 / Accepted: 3 November 2020 / Published: 30 November 2020

In recent years, graphene has attracted extensive attention in many fields. A nitrogen-doped graphene sheet was synthesized using a solid microwave-mediated method. An experimental electrode was thereafter prepared using nitrogen-doped graphene sheets (NGS), and the physical and electrochemical properties of nitrogen-doped graphene sheets were studied. A three-electrode supercapacitor test system with the experimental electrode also serving as one of the electrodes was built to conduct constant current charge/discharge, cyclic voltammetry, life span, and impedance spectrum tests on the experimental electrode. After 5000 cycles of charging/discharging at a current density of $0.5 \mathrm{~A} / \mathrm{g}$, the specific capacitance of the experimental electrode was $208.17 \mathrm{~F} / \mathrm{g}$ with corresponding capacitance retention of $98.56 \%$; when the current density was increased to $5 \mathrm{~A} / \mathrm{g}$, the specific capacitance of the experimental electrode after 5000 cycles of charging/discharging dropped to $157.31 \mathrm{~F} / \mathrm{g}$, indicating capacitance retention of $75.57 \%$. The effective series resistance was approximately $0.32 \Omega$. Owing to the stable properties and high relative spatial surface area of NGS, ions have a good contact rate and charge exchange capacity between the electrode and the electrolyte interface, thereby ensuring a stable supercapacitor capacitance.

Keywords: Graphene oxide; Nitrogen-doped graphene; Melamine; Microwave; Energy storage

\section{$\underline{\text { FULL TEXT }}$}

(C) 2021 The Authors. Published by ESG (www.electrochemsci.org). This article is an open access article distributed under the terms and conditions of the Creative Commons Attribution license (http://creativecommons.org/licenses/by/4.0/). 